\title{
บUisuersily
}

\section{Intergenerational Communication - an interdisciplinary mapping review of research between 1996 and 2017}

Law, J., Young, T., Almeida, J., \& Ginja, S. (2019). Intergenerational Communication - an interdisciplinary mapping review of research between 1996 and 2017. Journal of Intergenerational Relationships, 17(3), $287-310$. https://doi.org/10.1080/15350770.2018.1535349

Link to publication record in Ulster University Research Portal

Published in:

Journal of Intergenerational Relationships

Publication Status:

Published online: 31/07/2019

DOI:

10.1080/15350770.2018.1535349

\section{Document Version}

Author Accepted version

\section{General rights}

Copyright for the publications made accessible via Ulster University's Research Portal is retained by the author(s) and / or other copyright owners and it is a condition of accessing these publications that users recognise and abide by the legal requirements associated with these rights.

\section{Take down policy}

The Research Portal is Ulster University's institutional repository that provides access to Ulster's research outputs. Every effort has been made to ensure that content in the Research Portal does not infringe any person's rights, or applicable UK laws. If you discover content in the Research Portal that you believe breaches copyright or violates any law, please contact pure-support@ulster.ac.uk. 


\section{Intergenerational Communication - an interdisciplinary mapping} review of research between 1996 and 2017

James Law*a ${ }^{\text {a }}$, Tony Johnstone Young ${ }^{\mathrm{a}}$, Joana Almeida ${ }^{\mathrm{a}}$ and Samuel Ginja ${ }^{\mathrm{b}}$

${ }^{a}$ School of Education, Communication and Languages Sciences, Newcastle University, $U K$

${ }^{b}$ School of Psychology, Ulster University in the UK

*Correspondence to: Professor James Law, School of Education, Communication and Language Sciences, Newcastle University NEI 7RU UK e: james.law@ncl.ac.uk

Newcastle University, $U K$ 
Dr James Law is Professor of Speech and Language Science in the School of Education, Communication and Language Science at Newcastle University in the UK. His research foci include secondary data analyses of birth cohort following children through into adulthood and the science behind interventions to promote communication skills in children and young people.

Dr Tony Young is Reader in Applied Linguistics and Communication in the School of Education, Communication and Language Sciences at Newcastle University in the UK. His research interests focus on intergroup and intercultural communication in care and educational settings.

Dr Joana Almeida is a Research Associate in Education at the School of Education, Communication and Language Sciences at Newcastle University. Her main research interests focus on the internationalisation of higher education and cross-cultural communication. She is also interested in interdisciplinary research and innovative research methods in the social sciences.

Dr Samuel Ginja is a Research Associate in Behaviour Analysis at the School of Psychology at Ulster University in the UK. His main research interests include understanding and improving the health and wellbeing of young people. The present research was conducted whilst Dr Ginja was still a Research Associate at the Institute of Health and Society, at Newcastle University. 


\section{Intergenerational Communication - an interdisciplinary mapping review of research between 1996 and 2017}

Concerns have been raised regarding the limited opportunities for intergenerational communication both outside and within the family. This "mapping review" draws together empirical literature in the topic published since 1996. Three hundred and twenty four published studies met inclusion criteria, based on abstract review. The contents of each study were subjected to thematic analysis and nine broad themes emerged. These were (1) Dynamics of relationships, (2) Health \& Wellbeing, (3) Learning \& Literacy, (4) Attitudes, (5) Culture, (6) Digital, (7) Space, (8) Professional Development, (9) Gender \& Sexual Orientation. Studies commonly intersected disciplinary research areas. There was a marked rise across three key academic journals since 2007. An emergent finding was that a third of the studies relate to programs addressing intergenerational interventions, but many of these were primarily descriptive and failed to specify a primary outcome. Review implications and future research directions are discussed.

Keywords: intergenerational research; communication; relationships; programmes; interventions:

Type of submission: Research-based paper 


\section{Background}

Considerable concern has been raised in recent years about intergenerational divisions ${ }^{1}$, in part exacerbated by the thesis that older people have benefitted at the expense of the young (Willets 2010). Moreover, we live in in an increasingly atomized society where there are few fora for intergenerational communication. (Putnam, 1995). The apparent separation is exacerbated by stereotypical views that different age groups often have of each other - for example, in the widespread fear and uncertainty that older people express as to how best to respond to the young, and in younger people's frequent perceptions of negative and under-accommodative communication patterns in older people. Social isolation, particularly among older people, with related mental health and general wellbeing problems, is also an issue (Williams and Giles, 1996; 1998).

Communities often communicate in quite limited horizontal strata (the class, the club, the football team) and verticality across the generations, even within families once those initial bonds have been severed - may be minimal or confined to formal contexts (teacher and pupil in the classroom, boss and employee in the workplace and formal carer and resident in a care home). This potentially has an impact at all levels in a community but, where it is seen more clearly is in our treatment of our ageing populations. This separateness has been identified by politicians as an issue of societal concern especially for older people (ONS, 2015). Of particular concern is the sort of communication established between individuals from different age groups and/or cohorts.

\footnotetext{
${ }^{1}$ https://www.theguardian.com/commentisfree/2017/sep/04/generation-gap-social-divisionsyoung-old-age-segregation
} 
Scant attention has been paid to intergenerational communication related issues within the broader intergenerational field, despite the fact that communication with others is centrally important to people's sense of individual and social identity across the lifespan. This paper will, therefore, cast focus on this construct and the stock of knowledge developed over the past 21 years (1996-2017). By intergenerational communication, we mean:

The act of conveying meaning(s) within interactions and relationships between individuals from different age cohorts and/or groups. Intergenerational communication can involve interaction in and outside familial contexts (e.g., between a young person and a middle-age person and between grandparents and grandchildren, respectively). This sort of communication is prone to miscommunication as it is likely that people at different stages in the life-span have different communication styles, goals, needs and behaviours (Hummert, 2015).

Intergenerational communication concerns are also akin to Bourdieu's notion of social space as the multitude of interactions or "network of relationships" between agents within that space (Hardy 2012) do also depend on successful communication between individuals, including those from different generational strata. The relative position within that space is in part determined by the social capital of the individual concerned and is likely to be influenced by the type of large-scale social change that we are currently experiencing in western societies (Bourdieu 1992). Indeed Bourdieu has highlighted the need to understand the importance of intergenerational change in such space. One of the key instruments within social capital is the role played by linguistic capital, and the distribution of that capital "is related in specific ways to the distribution of other forms of capital (economic capital, cultural capital etc.) which define the location of the individual within the social space." (Thompson 1992, p.18). 
Given the central importance of linguistic capital, there is a need to focus more generally on intergenerational inclusion and the role that communication in general and intergenerational communication in particular can play in this process. This, in turn, raises the question of how effective interventions can be in making this communication more efficacious.. These issues have been discussed in the pages of this and other journals for two decades or so. Although the scholarly community recognises intergenerational studies as an academic field - see Larkin and Newman (1997), and Vanderven $(1999,2004)$ - its expansion is relatively recent and relates primarily to the work of human service professionals, educational end third-sector institutions in implementing intergenerational programmes that promote mutually satisfying relationships and interactions across generations.

As a field of intergenerational research matures, it becomes important to summarise emerging strands of activity and the role played by intergenerational communication in people's lives. Without such summarises it may be difficult to start to draw meaningful policy-related conclusions about the importance of this research strand. Thus, findings from a survey of research on the state of intergenerational relations in the UK demonstrated that the absence of a strong evidence-base may inhibit intergenerational communication at community level and its incorporation into public policy (see the work of the International Longevity Centre - Lloyd, 2008). Various publications and organisations worldwide have also sought to benchmark best practice in relation to intergenerational programmes and exchange. Third-sector organisations such as the Beth Johnson Foundation (BJF, http://www.bjf.org.uk) in the UK produced a study, in collaboration with the UNESCO Institute for Education, which defined conditions for successful intergenerational programmes and their importance for policy (see Hatton-Yeo \& Ohsako, 2000). 
One important contributory factor in consolidating the field is to map specialist literature. Mapping literature reviews play an important role in identifying knowledge gaps in a given research domain by mapping out and categorising existing literature. Mapping reviews differ from more conventional literature review methods in terms of focus, scope and outcomes, with the ultimate goal of conducting further reviews and/or primary research (Grant \& Booth, 2009; Petersen, Feldt, Mujtaba, \& Mattsson, 2008). Typically, mapping reviews are characterised by breadth rather than depth and a large number of studies are often assessed from the abstract only, e.g. (Bourret, Mogoutov, Julian-Reynier, \& Cambrosio, 2006) highlighting aspects such as study type, research methods, topics and/or content areas addressed, or target population (Kitchenham, Budgen, \& Pearl Brereton, 2011).

Our argument is that the time is ripe for such a review of literature in the burgeoning field of intergenerational communication. In the present review, we aim to contextualise the current state of the art of research on intergenerational communication, and to identify knowledge gaps which could usefully be addressed. To achieve these aims the review had the following overarching research question "What is the current state of intergenerational communication research?" From this research question, we derived the following two objectives:

(1) To provide an overview of intergenerational research

(2) To identify key topics and/or areas, intergenerational programmes, generational groups, and type of research methods

\section{Methods}

We selected a mapping review methodology because of its scope and time-efficiency in performing an unbiased aggregation of a large number of studies. The review was 
organised into five stages: (1) defining the research question(s) and objectives, (2) searching for primary studies (empirical, in our case), (3) screening of abstracts based on inclusion and exclusion criteria, (4) categorising papers (ad and post-hoc), and (5) data extraction and aggregation (Petersen et al., 2008), as illustrated by Figure 1.

[Figure 1 about here]

\section{Inclusion and Exclusion Criteria}

Studies were considered eligible for review under four inclusion criteria as follows:

(1) Published empirical studies from 1996 to February 2017

(2) Conducted in Western Post-Industrial English-speaking countries and published in English

(3) Reported intergenerational issues around communication, relations and/or interaction

(4) Focusing on two or more generations (based on age and/or life stage)

We considered as ineligible theoretical, opinion, secondary research papers, research protocols or validation of instruments. Sources were also excluded if their focus was not on communication as a psycho-social phenomenon - for example on genetics and or on the transmission of psychopathology or material inheritance. We also excluded sources where the distinction between generations and/or age cohorts or groups was not made clear, or where one of the generations included babies on the grounds that such circumstances are likely to raise rather different issues in relation to communication, for example, in terms of attachment or the identification of clinical problems.

\section{Search Strategy}

Systematic searches were conducted in February 2017 across four comprehensive social 
science databases: EBSCO Host, ProQuest Research Library, Web of Science, PsycInfo.

Non-systematic searches, such as hand searching across four relevant journals within the scope of our review, were not performed given that studies in these journals were identified by the scientific databases mentioned above. Key at this stage in the review process is that the search terms need to be as "inclusive" as possible to avoid missing studies. ThusThe following search terms were used:

$$
\begin{aligned}
& \text { (inter-generation* OR intergeneration* OR multi-generation* OR multigeneration* } \\
& \text { OR trans-generation* OR transgeneration*) AND (communicat* OR interact* OR } \\
& \text { conversation* OR dialogue* OR relation*) }
\end{aligned}
$$

One could argue that a more narrow set of search terms would give greater precision but experience suggests that when the terminology are imprecise this can reduce specificity at the expense of sensitivity.

\section{Selection of Studies}

References were identified, duplicates excluded, with papers which did not meet our inclusion criteria being removed based on title and abstract screening. Two independent reviewers from different fields of study in the social sciences (education and psychology) performed searches. Cases where these reviewers disagreed were recorded and resolved by discussion involving all four of the review authors, and so also included knowledge and perspectives from speech and language sciences, and from applied linguistics and communication.

A total of 8,942 references were retrieved from the four databases and exported to the reference management software EndNote (V.X7). Once duplicates were excluded, 6570 references were screened based on title and abstract. Of this total, 6246 studies were excluded based on our inclusion/exclusion criteria or insufficient abstract 
information on key scientific elements/aspects for aggregating data, namely: object of study, target population, research methods and key findings. As a result, 324 studies were selected for data analysis and the process by which they were identified is captured in Figure 2.

[Figure 2 about here]

\section{The separation of generational groups}

The definition of generational groups was based on both age and life stage. This twofold criterion was adopted because age groups are not always a clear indicator of a generational cohort. The course of life individuals are at should be also taken into account when categorising groups of individuals into generational groups.

This twofold criterion was particularly useful given that the information on abstracts was often limited and it was often unclear how the groups were defined in the original studies, as will be further explained below. For the purposes of our study, three generational groups were determined: Young (Y), Middle Age (M), Older Adults (O). It should be noted that the category "Young" addresses childhood-adolescent-and young adulthood in order to avoid compartmentalizing the data and to guarantee the accuracy of interpretation when the abstract provide only information on the life stage, and not necessarily on the age group as such. These are broad categories were necessary to reflect the fact that that the boundaries of a generational group and/or cohort were not always clearly stated in the abstracts themselves. Based on the combinations of communication dyads between the three groups, four different types of studies were possible to categorise:

(1) $\mathrm{YM}$ - studies involving young people and middle aged people

(2) YO - studies involving young people and older adults 
(3) $\mathrm{MO}$ - studies involving middle aged people and older adults

(4) YMO - studies involving young people, middle aged people, and older adults

\section{Data Extraction and Analysis}

An Excel file was created to extract and aggregate data from the abstract of the 324 selected studies according to each of the following categories: (1) Year of publication, (2) Journal, (3), Topics or thematic areas, (4) Programme/intervention, (5) Familial (6) Generational group, and (7) Type of research methods These categories allowed reviewers to create a framework that is both case and theme-based whilst making the analytical process systematic, transparent and dynamic (Ritchie, Lewis, McNaughton Nicholls, \& Ormston, 2014). Themes became, therefore, the basic coding units, here understood as patterns found in the information that at minimum describes and organizes possible observations and at maximum interprets aspects of the phenomenon" (Boyatzis, 1998, p. 4).

[Table 1 about here]

To attain accuracy of interpretation, we drew on the interdisciplinary expertise of the project team, encompassing education, psychology, applied linguistics and speech and language sciences, and were guided by the following protocol. An initial sample of 50 studies was double-coded independently by two of the authors, and assigned the themes. Discrepancies were resolved by discussion between these two authors in the first instance. The two other authors then independently checked this sample, and the whole team agreed appropriate coding for the sample. This procedure was then extended to the whole database of 324 abstracts to ensure a consistent interpretation throughout the remaining categorisation (Ritchie \& Lewis, 2003). Once completed, the Excel file data set was imported to IBM SPSS (V.22) for quantitative analysis. 


\section{Results}

In addition to categorising the themes under examination in the sampled studies, results were also grouped according to: (a) the year and academic outlet, (b) familial and nonfamilial foci, (c) generational groups and/or cohorts, (d) type of research methods, and (e) type of intergenerational programmes and/or interventions.

Year and Academic outlet

Data showed an increase in the number of intergenerational studies from 7 in 1996 to 32 in 2016, although this increase was uneven with a marked rise from 2007 onwards. Figure 3 about here

Included studies spanned 157 journals and, of these, only 17 journals carried three or more papers relevant to the present enquiry. The three most frequent journals were: the Journal of Intergenerational Relationships (46;28.4\%), which is the only journal focusing exclusively on the intergenerational field, and the Journal of Marriage and Family $(\mathrm{n}=20 ; 12.3 \%)$ and Educational Gerontology $(\mathrm{n}=16 ; 9.9 \%)$. Others such as Childhood, Universal Access in the Information and Society, The International Journal of the Education and the Arts clearly have a very different focus and only occasionally published this type of content.

[Figure 4 about here]

Themes

Nine different themes were identified from the thematic analysis of abstracts based on content areas and key terms. The description of these themes is provided in Table 2 below.

[Table 2 about here] 
The three most common topics in our data set were: Dynamics of Relationships $(n=149$ : 46.0\%), followed by Health \& Wellbeing $(\mathrm{n}=109 ; 33.6 \%)$ and Learning \& Literacy $(\mathrm{n}=75 ; 23.2 \%)$. Within Health \& Wellbeing, 10 studies addressed a clinical issue, for example dementia, depression, or youth at risk of substance misuse, or were conducted in a therapeutic context. As some studies addressed more than one theme, an additional analysis of overlap between the three most common themes was carried out. Figure 5 shows the level of overlap between these themes. The greatest intersection was between the two categories Health \& Wellbeing and Dynamics of Relationships $(n=45)$. When considering the three most frequent themes all together, the degree of overlap comes down to 2 studies only. This is unsurprising given that the emphasis in Learning and Literacy is on knowledge transfer and learning, which is unrelated to issues of health and well being but can involve relationships between generational groups and/or cohorts to foster mutual knowledge, learning and skills' development.

[Figure 5 about here]

\section{Familial and non-familial foci}

Of the 324 studies identified by the search criteria, 180 were familial (55.6\%), i.e. explicitly involved interactions between family members (e.g., parents and children, grandparents and grandchildren, in-laws). Non-familial studies ( $n=144 ; 44.4 \%)$ were those addressing interactions between individuals of different generational groups and with no explicit mention to family links, such as volunteers, teachers, students or professional caregivers. This finding accords with the broader intergenerational literature showing that patterns of intergenerational interactions (and communication, therefore) although usual in familial contexts, are becoming more common in different 
aspects or settings of daily life - in the workplace, social settings, schools, and at home, while overall levels of interaction and communication are seen to be falling.

[Table 3 about here]

In most cases, there were significant differences between familial and non-familial studies in terms of the topics addressed (Table 3). Studies on Dynamics of Relationships were highly significantly more likely to be familial $(\mathrm{p}<.001)$, whereas studies on Learning \& Literacy and Attitudes were highly significantly more likely to be nonfamilial $(\mathrm{p}<.001)$. The relationship between familial studies and the topics Culture and Space was also significant $(\mathrm{p}<.05)$, as well as the relationship between non-familial studies and the topic Digital $(\mathrm{p}<.05)$. There was no association between familial/nonfamilial studies and the topics Health \& Wellbeing and Gender \& Sexual Orientation. A comparison between familial and non-familial studies was not possible for the topic Professional Development as the assumptions of the statistical test were not met. This is likely due to the fact that the vast majority of studies about professional development were non-familial as professional environments (e.g. companies) usually involve people who are not relatives.

\section{Generational Groups and/or cohorts}

Overall, 253 studies (78.1\%) involved young people, 133 middle aged people (41.0\%), and 244 older adults $(75.3 \%)$. The most frequent combination of generational groups was YO $(\mathrm{n}=145 ; 44.8 \%)$. The second most frequent combination was YM on a par with YMO ( $=46 ; 14.2 \%)$. There were 38 studies researching both middle-aged people and older adults $(11.7 \%)$. Forty-nine studies were marked as unclear (15.1\%), including: studies with 'parents and children' without indication of age or life stage (e.g., 'young' 
or 'old'); studies referring to a 'younger' and an 'older' group only; studies where only one generational group was identifiable.

It should be noted that results, and the prevalence of Young and Old (YO) in our results might be also related to the search terms used (*inter-multi-trans generational) and to the inclusion of childhood-adolescent-young adulthood in the category Young (YO), thus affecting the range of generational groups identified in the sampled studies. In this regard, it is important to note that one can find several studies in developmental psychology journals that focus on parent-child interaction, without necessarily using the terms inter, multi or trans- generational. This is primarily because the focus of the activity was not intergenerational communication but some aspect of the child's interaction skills or their educational attainment.

\section{Type of Research Methods}

Studies fell into four mutually exclusive categories of research methods: qualitative, quantitative, both or unclear. Qualitative studies $(n=145 ; 44.8 \%)$ typically included: interviews, focus groups, observation of interactions and ethnographic research. Quantitative studies ( $\mathrm{n}=95 ; 29.3 \%)$ consisted primarily of surveys and instruments aimed at testing or measuring associations or correlations, and programmes using experimental or non-experimental designs. Some studies used both types of methods $(\mathrm{n}=14 ; 14.3 \%)$, even if studies were predominantly of one type but incorporated some elements of the other type. Studies where the type of methods was unclear corresponded to cases where this information could not be obtained from the abstract $(\mathrm{n}=70 ; 21.6 \%)$.

\section{Type of intergenerational programmes and/or interventions}

One of the emergent findings from the review were the number of programmes or interventions designed to facilitate intergenerational communication. One third of our 
studies addressed and/or included programmes $(n=108 ; 33.3 \%)$, including interventions or projects, of which 15 were familial (13.9\%), i.e. targeted specifically at family members. There was a wide range of activities reported within these programmes, but it was not possible to develop a taxonomy of programmes due to the limited information available on abstracts and to some inconsistencies in the use of programme names across studies. Frequent labels for such programmes included: 'service learning', 'mentoring', "community programmes", or 'education programmes'.

Out of the 108 programmes, the most common topic addressed was Learning \& Literacy ( $\mathrm{n}=48 ; 44.4 \%)$, followed by Health \& Wellbeing and Attitudes.The least frequent programme topics were Space and Gender \& Sexual Orientation. Although Dynamics of Relationships was the most frequent topic in the total sample of 324 studies, it was one of the least frequent programme topics.

Figure 6 about here

A post-hoc decision was made to analyse programme or intervention studies in more detail, given their potential to inform the development and evaluation of future intergenerational programmes. Out of 108 programme studies, we selected those with an experimental or quasi-experimental design, i.e. studies with experimental and control groups and with or without randomisation of participants or groups. Ten studies met these criteria (see Table 4). However, the paper from one study could not be found (Aseltine, Dupre, \& Lamlein, 2000), resulting in 9 studies (8.3\%) being subject to full paper screening. Two different studies involved the same intervention, which corresponds to a total of 8 programmes: these are summarised in Table 4.

[Table 4 about here]

The programme setting was either the school (5/8) or adult living facilities (3/8). There was an equal distribution of the target age groups: young people (3/9), older 
adults (3/9), or both (3/9). Programmes were generally of short duration ( $\leq 5$ months), and two of them were ongoing. Amongst the most common programme activities which aimed to enhance were writing or reading (5/8), and those aimed at fostering arts and creativity (4/8).

Outcomes of these studies revolved predominantly around health and wellbeing, especially in older adults (6/9), and attitudinal measures (5/9). In terms of effectiveness, one study reported a significant difference in favour of the experimental group (1 outcome), whereas another study reported no significant differences at all (3 outcomes). Mixed results were found in all seven other studies, i.e. significant differences between groups were observed in some outcomes but not in others, and the distinction between primary and secondary outcomes was usually lacking. Five of these seven studies assessed four outcomes or more, and comparisons between intervention and control groups were largely non-significant.

The only two randomised controlled trials reported either no significant differences at all (3 outcomes), or mostly no differences (4 out of 5 outcomes), and none of them used blinding procedures of any sort. Three studies were follow-up assessments conducted between 9 months to 9 years after the end of the programme. Each of these follow-up studies assessed multiple outcomes, with mixed and mostly non-significant results being reported within studies. Another study which had identified statistical differences immediately post intervention found that these gains had washed out at seven week follow up assessment.

\section{Discussion}

To the best of our knowledge, this was the first mapping review to provide an overview of research on intergenerational communication and to identify key themes and 
methodological approaches. Out of 324 studies, most explicitly involved relatives and interactions between young people and older adults. One third of studies consisted of programmes, of which only $8.3 \%$ had used a (quasi-) experimental design.

An important part of this mapping review was the identification of the most prevalent topics in this area of research. The choice of labels for themes was informed by key terms and subject matter (e.g., Health \& Wellbeing, Digital, Culture). 'Dynamics of Relationships' has also been used before in the context of intergenerational relationships to refer to the same processes - e.g., alienation and reciprocity (Vanderven, 2004). It is difficult to know how representative our data are of the wider intergenerational literature across all discipline areas. However, our typology seems broad enough in scope and robust enough in design to capture key subjects addressed by some of the existing literature reviews in the field of intergenerational research, e.g., reciprocity as sub-topic of Dynamics of Relationships (Knight, Skouteris, Townsend, \& Hooley, 2014), wellbeing (Hye-Jin, Kang, \& Johnson-Motoyama, 2016), attitudes and professional development (Tullo, Spencer, \& Allan, 2010), learning and culture (Lui, 2015), and space (van Vliet, 2011).

The small number of studies on Gender \& Sexual Orientation observed in our review is consistent with findings of wider scientific research in which females, LGBT people and other minorities are often understudied (e.g., Beery \& Zucker, 2011; Bogart, Revenson, Whitfield, \& France, 2014). For practical reasons, we have only provided data on the overlap between the three most common topics, and this overlapwas found to be considerable. For instance, most studies on Health \& Wellbeing $(62 / 109 ; 56.9 \%)$ were also about Dynamics of Relationships or Learning \& Literacy. Nevertheless, some studies may focus only on one of these topics and not on the other two (e.g. (Aquilino, 1999), which suggests that the distinction may be useful. 
There were 180 studies involving family members (55.6\%), which suggests a rough balance between familial and non-familial research. An interesting finding was that some topics were predominantly (or exclusively, in the case of Professional Development) associated to either familial or to non-familial studies. This difference was not significant for Health \& Wellbeing and for Gender \& Sexual Orientation, but it was significant for all other topics, except Professional Development for which the number of observations was insufficient. Altogether, these findings suggest that more attention should be paid to the topics of: (a) Dynamics of Relationships among nonfamily members, (b) Culture among non-family members, (c) Space among non-family members, (d) Learning \& Literacy among family members, (e) Attitudes among family members and (f) Digital among family members. However, it is possible that some studies here classified as non-familial would actually be familial if we had reviewed the full article. Further research is needed to corroborate these findings.

Most studies were qualitative $(n=145 ; 44.8 \%)$. This is consistent with previous research which has found that, to date, most intergenerational programmes in the UK have been evaluated through qualitative techniques such as interviews and focus groups (see Lloyd, 2008).

The number of intergenerational programmes $(n=108 ; 33.3 \%)$ indicates that there is a considerable body of available research on such programmes, although only 15 of these programmes were familial (13.9

With the exception of the nine programmes studies which were fully screened, data extraction was based exclusively on the abstract, which is a limitation that we acknowledge. Abstract-based mapping reviews have been published in other areas, although they have tended to cover a larger number of studies than our review, and they sometimes use content analysis software (e.g., Bourret et al., 2006; Cretchley, Rooney, 
\& Gallois, 2010). Due to our focus on intergenerational communication, but also time and budget constraints, our mapping review had a narrower scope of studies and data were analysed manually. Combining manual analysis with software data mining may increase the robustness of the analytical process, but some mapping studies have found manual analysis to be comparable to content analysis software (Ali, Yong, Soar, \& McClymont, 2015; Grech, Horberry, \& Smith, 2002).

Finally, it is important to return to the concerns raised in the introduction about the state of intergenerational communication. While it is clear that there is a concern about the breakdown of relationship across the generations it remains unclear to what extent this is ubiquitous or whether it is especially relevant for specific groups in society, perhaps those who are more economically stressed. Given the potential role of social media it seems likely that intergenerational geographical dispersion together with the many different familial configurations, often characterised as crucial elements in the decline of the nuclear family, are less of a problem in terms of communication than they were are the start date for our review. It may be that intergenerational tensions while always present to some extent within families are becoming especially salient in nonfamilial contexts and it is in these spaces (to use Bordieu's term) where the misunderstandings and resentments identified by newspapers and politicians potentially arise. Indeed, as we have seen in Figure 4, it is clear than the balance between investigations that focus on familial or non-familial aspects of intergenerational communication differs considerably. The opportunities to generate social and cultural capital between generations no longer exists for many, and thus individuals are suspended within their generation, only rarely having access to that of others with networks of relationships confined to their own filter bubble. Whether it is only possible to bemoan this separateness, resigning ourselves to changes in society or whether it is 
possible to redress the balances through programmes and interventions remains a moot point. By teasing out some of the different elements of intergenerational interaction we maintain that we have gone some way to operationalising a solution to the problem but there remains much more to do.

\section{Implications}

Our overview of intergenerational research can be used as a broad base not only for mapping research strands, but also for providing information pertinent to practitioners and, potentially, policy makers . With an emphasis on the implications for research and in anticipation of additional research work on intergenerational communication subsequent to this mapping review, our findings allow us to identify a number of research gaps and potential areas for improvement. In terms of themes covered, while some content areas like "Dynamics of Relationships" were dominant, other strands like "Gender and Sexual Orientation" would benefit from further research. The same applies to members of minority groups where intergenerational communication may play out in different ways. This is particularly important if intergenerational relationships and communication between members of different generations are to be key indicators of a cohesive and functioning society across all its community and age groups. Similarly issues of space remain relatively understudied. The increasing number of older adults in care suggests that more opportunities to develop and test intergenerational activities in those settings may be possible. As such, we will benefit from studying how physical conditions can be arranged to enhance contact and communication between younger and older people. Studies around professional development were scarce and mainly consisted of healthcare professionals providing services to older adults or professional development activities or training on intergenerational interactions to embed in 
healthcare curricula. There are clearly many more opportunities to explore training relevant across generations.

Although a relatively high proportion of our studies focused on interventions, very few evaluated them with rigorous, high quality research methods. Programme activities need to be described in a consistent and clear manner to allow reproducibility and evaluation. Standardised taxonomies can be employed where possible (for example, see details of a taxonomy for behaviour change techniques (Michie et al., 2011). Study designs should include randomised controlled or quasi-experimental designs when possible, as these are considered the gold standard for the evaluation of interventions and so will carry more weight when informing policy. Since many programmes take place in care homes or schools, a cluster randomised design may be more appropriate and feasible. Similarly qualitative study designs, which are relatively dominant in this literature, for example those addressing perceptions, or process/ acceptability issues, rather than efficacy as such, need to be rigorous to inspire greater confidence. Where appropriate, both quantitative and qualitative methods may be combined for a richer and more rigorous and fine-grained description of the phenomenon under study.

Underpinning all the included studies is the challenge of measuring and evaluating communication in a systematic fashion. Programmes need to employ valid and reliable outcome measures, with a clear specification of what the main outcome is when multiple ones are assessed. Our review suggested that the identification of primary outcomes, and thus an explicit identification of the purpose of the intervention was relatively uncommon, even though such measures do exist. Clearly, this is an area which needs to be explored further.

In addition to the need for primary studies to fill the knowledge gaps identified above, secondary studies are needed to aggregate and critically evaluate primary 
research on intergenerational communication-related issues, which seldom emerged as an explicit object of analysis in the sample studies. These kind of studies are essential for theory construction whilst providing a roadmap that may contribute to wellsustained research activities and inform the decisions for policy, research and practice on different intergenerational aspects, including communication. Moreover, a study's conceptualisation and operationalisation of generational groups and/or cohorts need to be clearly stated in abstracts, as well as the procedural and methodological steps taken to analyse these groups. In a considerable number of abstracts these two central pieces of information were missing.

A final implication of our findings relates to programmes. It is clear is that more work should be devoted to developing and evaluating programmes involving family members of different generations as these may deal with different aspects of intergenerational interactions and communication (Knight et al., 2014). Our post-hoc analysis suggested that more high quality studies are necessary before the effectiveness of these intergenerational programmes can be established, in the context of improving health and wellbeing, or age-related attitudes, for example. This implication is admittedly drawn from a small number of studies $(n=9)$, although these are likely to be of greater methodological rigour than the other programme studies which were excluded due to lacking a controlled design (99 out of 108 studies). However, it is not possible at this point to state how representative the nine studies are of all intergenerational programmes given the way that they were identified.

Limitations of the present study 
There are inevitable trade-offs between breadth and depth in mapping reviews. A more comprehensive analysis of our included studies would have allowed to us to articulate in more detail the nature of the endeavour in the studies themselves but would not been possible given the available time.

The categorisation of the studies also raised some challenges given the missing information in some of the study abstarcts. However, this highlighted areas that need further improvement, namely the clarity needed regarding the adopted understanding of generational group and/or cohort and specification of the type of research methods. This limitation led us to adopt broad categories to how defined generational group given that this information was not always clear-cut or based on different assumptions: age and life stage. This also applies to the 70 papers where it was simply not possible to identify the methodology from the abstract. It seems unlikely in this field that the structure of abstracts could be predetermined as it is for example in by the Consort criteria for describing randomised trials (http://www.equator-network.org/reportingguidelines/consort/) but it would help if more investigators were clearer in their abstracts about what they had actually done and, of course, this pulls through to key wording and indexing of papers more generally.

As we have already acknowledged, while we identified programmes and intervention studies through our search strategy, we do not claim this aspect of the review to be exhaustive and the area would warrant further enquiry in future. Finally, we spoke in the introduction about the need for evidence-informed policy in this area. This, of course, requires consistent findings based on sound empirical evidence. The studies we have identified are, at this stage, indicative of the importance of the topic from a societal perspective. We are not at a stage where policy recommendations would be feasible from the studies that we have identified. 


\section{Conclusions}

The domain of intergenerational communications research has expanded considerably in the past decades and this is reflected in the range and variety of topics and analytical approaches adopted. Nevertheless, our review demonstrates that there are a series of component elements which could be tested in subsequent reviews. It is also important to emphasise the multi-disciplinary focus of the domain. No one academic or professional group "owns" intergenerational communication or the broader intergenerational field and thus represents a truly interdisciplinary enterprise.

While the review contributes to a broader picture at a descriptive level, more high-quality quantitative or mixed methods research is necessary if we are to evaluate interventions and, in turn, develop new ones. We hope the questions and gaps highlighted in this mapping review will have an impact on researchers in the field of intergenerational communication; by pointing towards the most appropriate lines of inquiry and ultimately to optimising the allocation of resources, which are often scarce and fragmented (see for example ongoing discussions about the provision of local authorities to services for youth and to care for the elderly).

In addition to contributing to the systematisation of the state of the art of intergenerational research, our mapping review and the critical evaluation it provides may inform the efforts and decisions of both researchers, practitioners and policy makers and, therefore, help bridging the gap between theory and practice. 


\section{References}

Ali, O., Yong, J., Soar, J., \& McClymont, H. (2015). Level of policy for cloud computing adoption in Australian regional municipal government: An exploratory study. Paper presented at the Proceedings of the International Conference on Grid Computing and Applications (GCA).

Aquilino, W. S. (1999). Two views of one relationship: Comparing parents' and young adult children's reports of the quality of intergenerational relations. Journal of Marriage and the Family, 858-870.

Aseltine, R. H., Dupre, M., ., \& Lamlein, P. (2000). Mentoring as a drug prevention strategy: An evaluation of Across Ages. Adolescent and Family Health, 1(1), $11-20$.

Beery, A. K., \& Zucker, I. (2011). Sex bias in neuroscience and biomedical research. Neuroscience \& Biobehavioral Reviews, 35(3), 565-572.

Bogart, L. M., Revenson, T. A., Whitfield, K. E., \& France, C. R. (2014). Introduction to the special section on Lesbian, Gay, Bisexual, and Transgender (LGBT) health disparities: where we are and where we're going. Annals of Behavioral Medicine, 47(1), 1-4.

Bourdieu, P. (1992) Language and Symbolic Power. Cambridge UK: Polity Press.Bourret, P., Mogoutov, A., Julian-Reynier, C., \& Cambrosio, A. (2006). A new clinical collective for French cancer genetics: A heterogeneous mapping analysis. Science, Technology, \& Human Values, 31(4), 431-464.

Boyatzis, R. E. (1998). Thematic analysis and code development. Transforming qualitative information. Thousand Oaks, CA: Sage.

Cretchley, J., Rooney, D., \& Gallois, C. (2010). Mapping a 40-year history with Leximancer: Themes and concepts in the Journal of Cross-Cultural Psychology. Journal of Cross-Cultural Psychology, 41(3), 318-328.

Grant, M. J., \& Booth, A. (2009). A typology of reviews: an analysis of 14 review types and associated methodologies. Health Information and Libraries Journal, 26(2), 91-18. doi: 10.1111/j.1471-1842.2009.00848.x

Grech, M. R., Horberry, T., \& Smith, A. (2002). Human error in maritime operations: Analyses of accident reports using the Leximancer tool. Paper presented at the Proceedings of the human factors and ergonomics society annual meeting.

Hatton-Yeo, A., \& Ohsako, T. (2000). ntergenerational Programmes: Public Policy and Research Implications: An International Perspective. Hamburg and Stoke-onTrent: UNESCO Institute for Education and Beth Johnson Foundation.

Hye-Jin, K., Kang, H., \& Johnson-Motoyama, M. (2016). The psychological well-being of grandparents who provide supplementary grandchild care: a systematic review. Journal of Family Studies, 1-24. doi: 10.1080/13229400.2016.1194306

Hummert, M. L. (2015). Intergenerational Communication. In W. Donsbach (Ed.), The Concise Encyclopedia of Communication (pp. 273-275). West Sussex: Blackwell Publishing.

Kitchenham, B. A., Budgen, D., \& Pearl Brereton, O. (2011). Using mapping studies as the basis for further research - A participant-observer case study. Information and Software Technology, 53(6), 638-651. doi: https://doi.org/10.1016/j.infsof.2010.12.011

Knight, T., Skouteris, H., Townsend, M., \& Hooley, M. (2014). The Act of giving: A Systematic review of nonfamilial intergenerational interaction. Journal of Intergenerational Relationships, 12(3), 257-278. doi: 10.1080/15350770.2014.929913 
Larkin, E., \& Newman, S. (1997). Intergenerational studies. Journal of Gerontological Social Work, 28(1-2), 5-16. doi: 10.1300/J083v28n01_03

Lloyd, J. (2008). The state of intergenerational relations today. A Research and discussion paper Retrieved from www.ilcuk.org.uk

Lui, P. P. (2015). Intergenerational cultural conflict, mental health, and educational outcomes among Asian and Latino/a Americans: Qualitative and meta-analytic review: American Psychological Association.

Michie, S., Ashford, S., Sniehotta, F. F., Dombrowski, S. U., Bishop, A., \& French, D. P. (2011). A refined taxonomy of behaviour change techniques to help people change their physical activity and healthy eating behaviours: The CALO-RE taxonomy. Psychology \& Health, 26(11), 1479-1498.

ONS. (2015). Office for National Statistics. Measuring National Well-being: Insights into Loneliness, Older People and Well-being, 2015. Retrieved 29/06/2017, from

https://www.ons.gov.uk/peoplepopulationandcommunity/wellbeing/articles/mea suringnationalwellbeing/2015-10-01\#older-people-well-being-and-loneliness

Petersen, K., Feldt, R., Mujtaba, S., \& Mattsson, M. (2008). Systematic mapping studies in software engineering. Paper presented at the In: Proceedings of the 12th International Conference on Evaluation and Assessment in Software Engineering.

Putnam, R. D. (1995). Bowling alone: America's declining social capital. Journal of democracy, 6(1), 65-78. Ritchie, J., \& Lewis, J. (2003). Qualitative research practice. A guide for social science students and researchers. London: Sage.

Ritchie, J., Lewis, J., McNaughton Nicholls, C., \& Ormston, R. (2014). Qualitative research practice : A guide for social science students and researchers London: Sage.

Thompson, J.B. (1992) Editors Introduction to P. Bourdieu, Language and Symbolic Power Cambridge UK: Polity PressTullo, E. S., Spencer, J., \& Allan, L. (2010). Systematic review: helping the young to understand the old. Teaching interventions in geriatrics to improve the knowledge, skills, and attitudes of undergraduate medical students. Journal of the American Geriatrics Society, 58(10), 1987-1993.

van Vliet—, W. (2011). Intergenerational cities: A framework for policies and programs. Journal of Intergenerational relationships, 9(4), 348-365.

Vanderven, K. (1999). Intergenerational theory: The missing element in today's intergenerational programs. In V. Kuehne (Ed.), Intergenerational programs: Understanding what we have created (pp. 33-47). Binghamton, NY: The Haworth Press.

Vanderven, K. (2004). Intergenerational theory in society: Building on the past, questions for the future. Journal of Intergenerational Relationships, 2(3-4), 7594. doi: 10.1300/J194v02n03_07

Willets, D. (2010) The Pinch: How the Baby Boomers Took Their Children's Future. London: Atlantic Books.

Williams, A. \& Giles, H. (1996). Intergenerational conversations: Young adults' retrospective accounts. Human Communication Research, 23, 220 - 250.

Williams, A. \& Giles, H. (1998). Communication of ageism. In M. Hecht (Ed.) Communicating prejudice: Tolerance and intolerance (pp. $136-160$ ). Thousand Oaks, CA: Sage. 
FIGURES AND TABLES

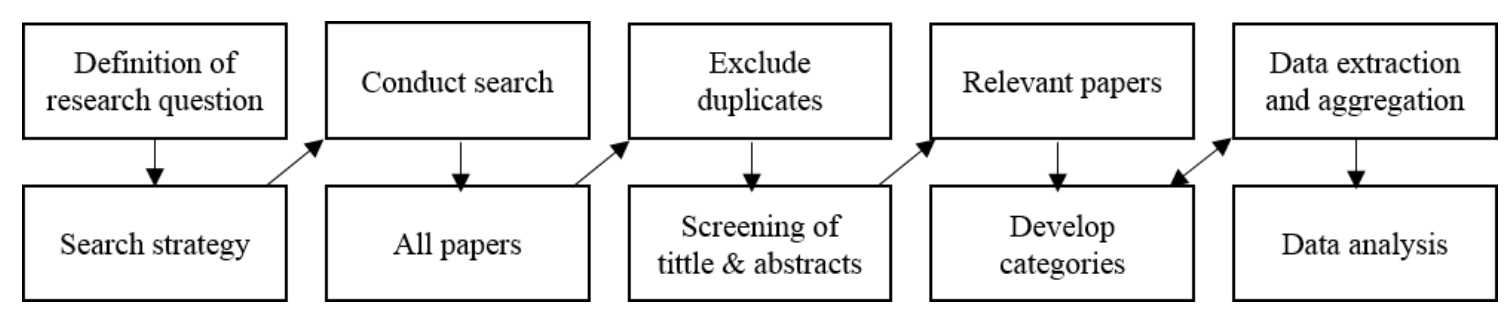

Figure 1. Systematic Mapping Process - Adapted from Petersen et al. (2008). 


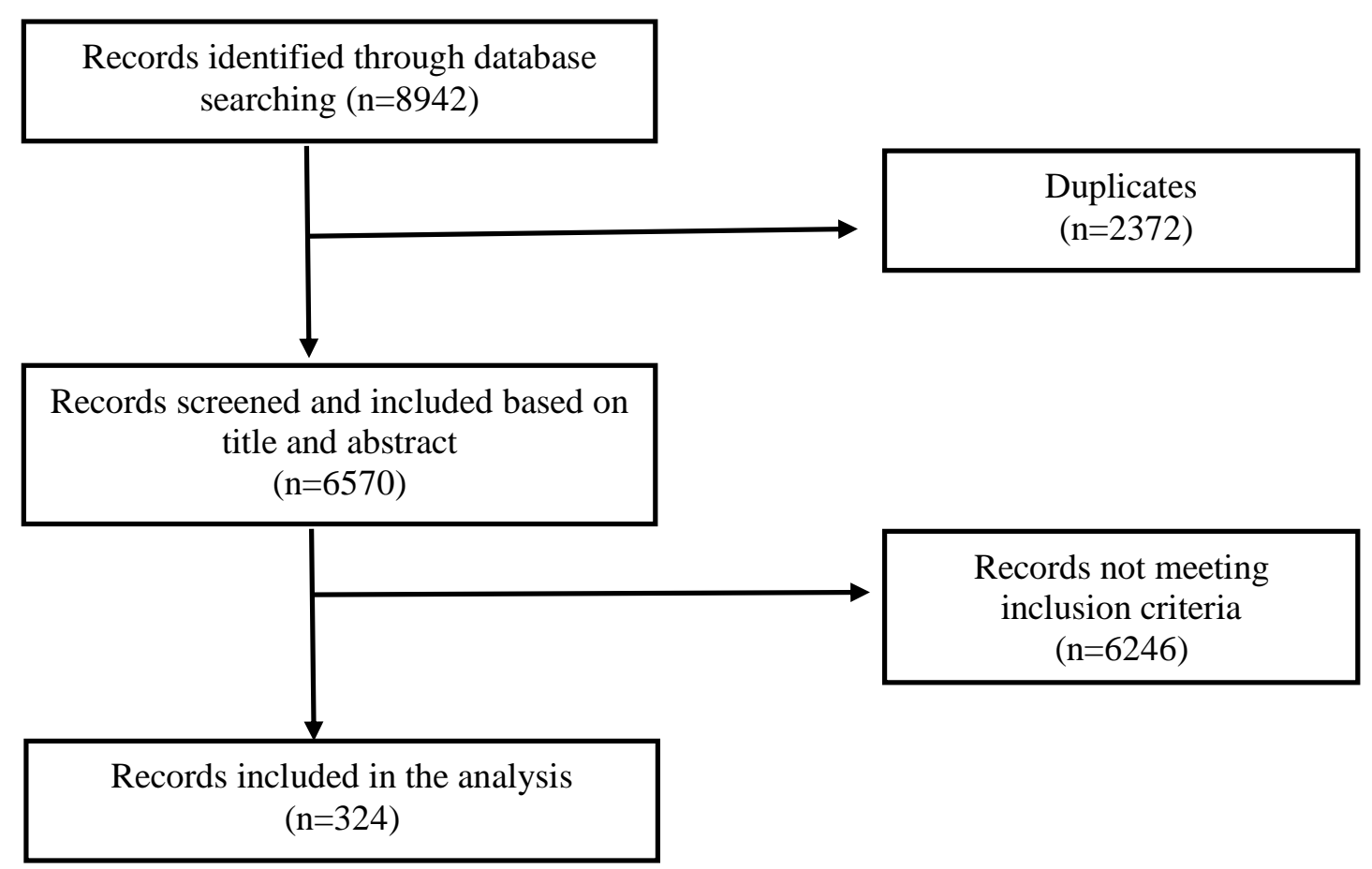

Figure 2. Selection process for reviewed articles. 


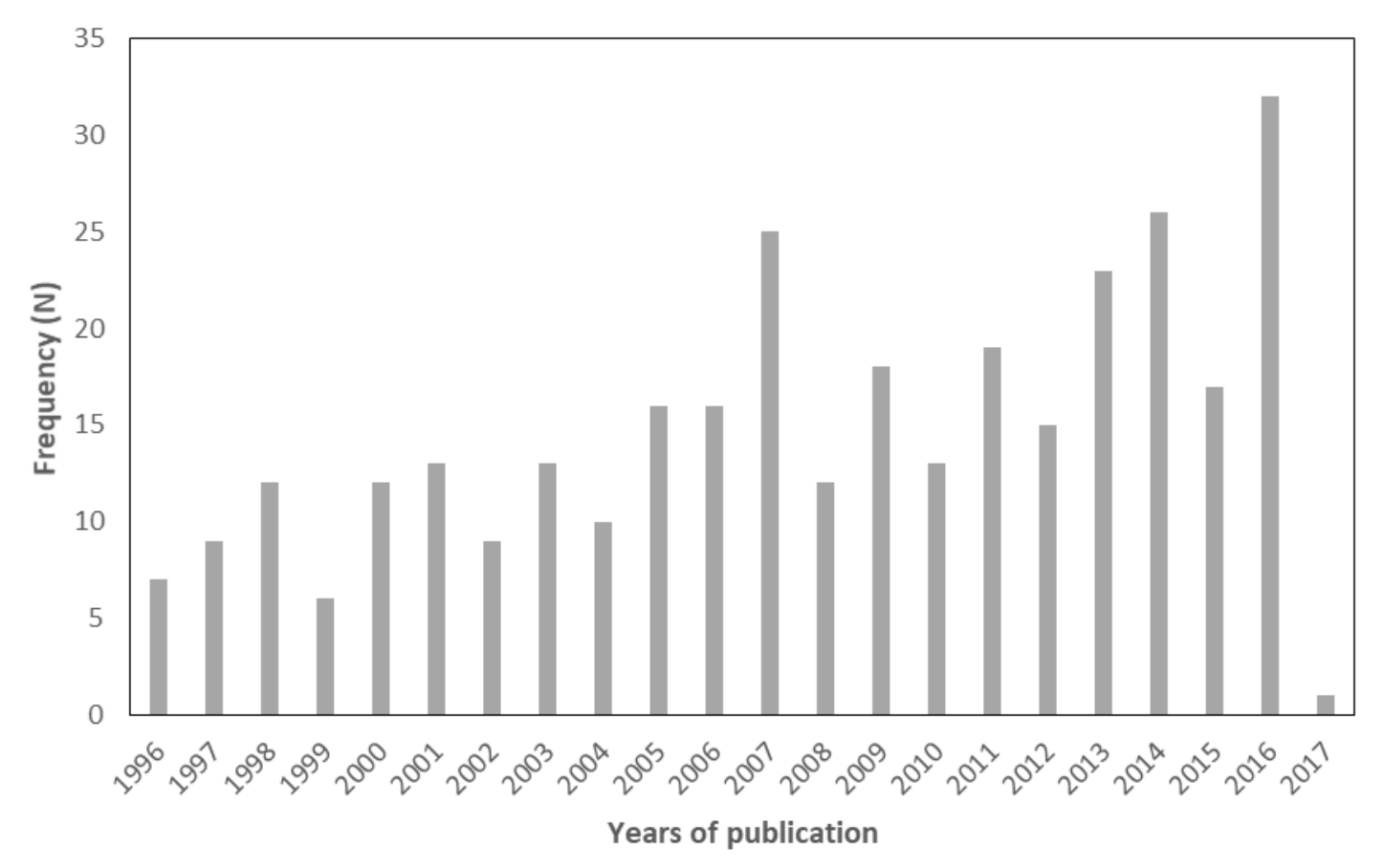

Figure 3. Number of intergenerational studies between 1996 and $2016(\mathrm{~N}=324)$. 


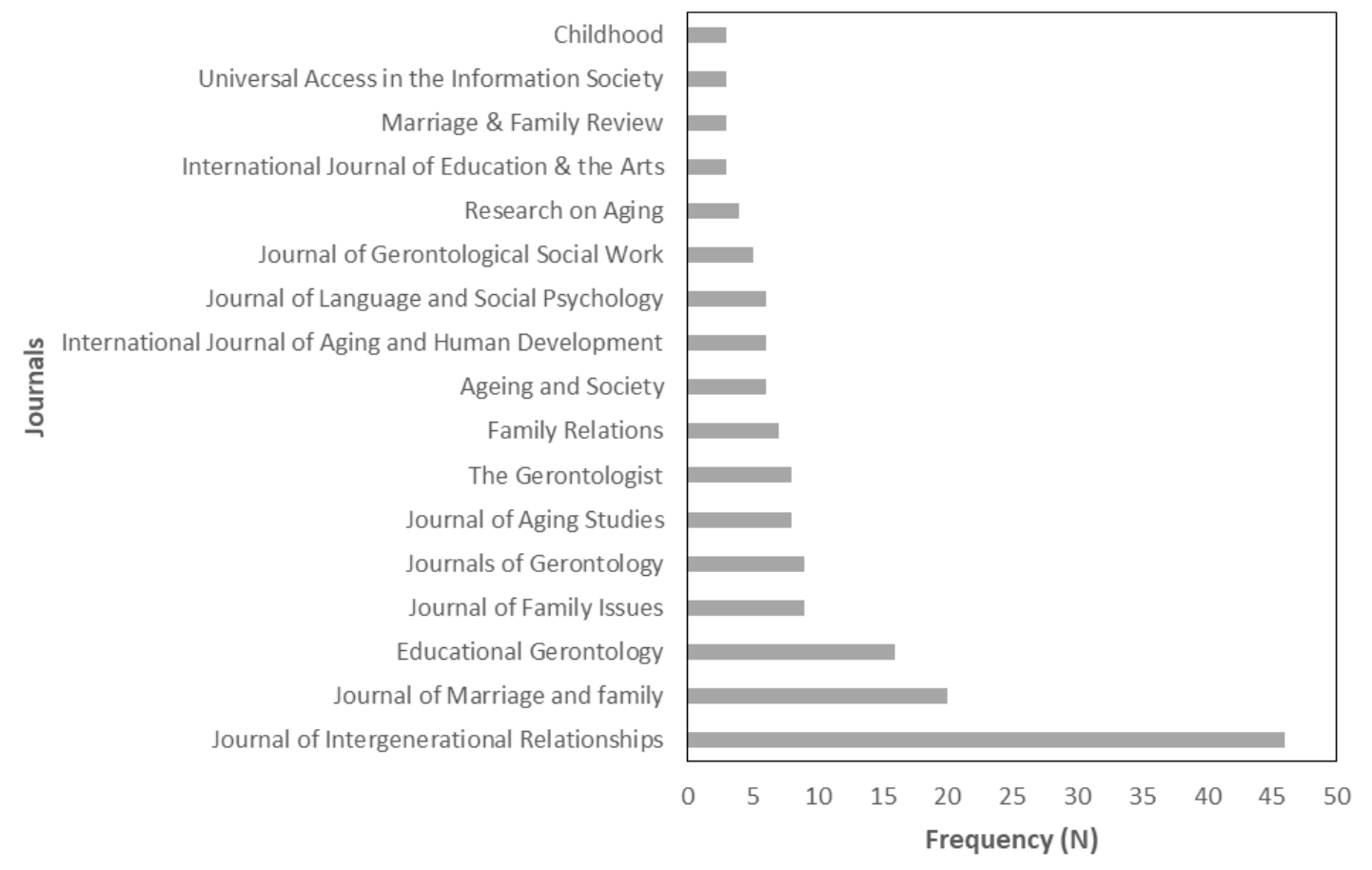

Figure 4. Range of publications including three or more studies identified in the review 
Health \&

Wellbeing

Dynamics of

$(n=109)$

relationships $(n=149)$

$\mathrm{n}=47$

$n=43$

$\mathrm{n}=99$

$\mathrm{n}=17 \quad \mathrm{n}=2$

$\mathrm{n}=5$

$\mathrm{n}=51$

Learning \&

Literacy $(n=75)$

Figure 5. Areas of overlap between the three most common categories 


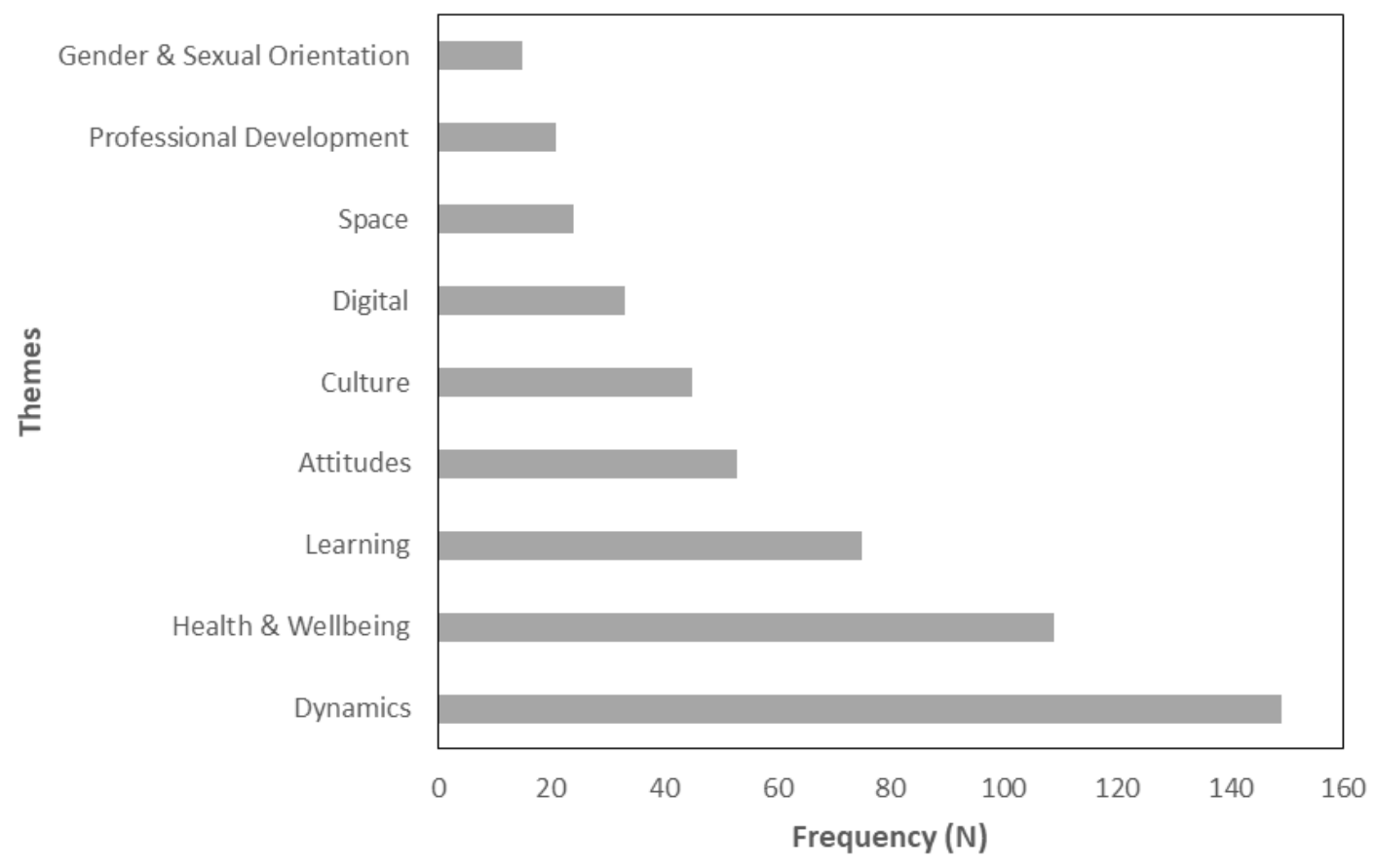

Figure 6. Topics addressed by programmes $(\mathrm{N}=108)$. 
Table 1 - Data extraction categories.

\begin{tabular}{ll}
\hline Categories & Sub-categories \\
\hline 1. Year of publication & Year \\
2. Journal & Journal name \\
& $*$ Dynamics of relationships \\
& $*$ Health \& Wellbeing \\
& $*$ Learning \& Literacy \\
& $*$ Attitudes \\
& $*$ Culture \\
3. Topics & $*$ Digital \\
& $*$ Space \\
& $*$ Professional development \\
& Yes/No \\
4. Programme & \\
& Yes/No \\
5. Familial & $*$ Young \\
6. Age or intergenerational & $*$ Middle \\
group & $*$ Old \\
& $*$ Quantitative \\
7. Type of research methods & $*$ Qualitative \\
& $*$ Both \\
& $*$ Unclear
\end{tabular}

Note. ${ }^{1}$ Any programme, programme features or interventions designed to produce changes and/or specific outcomes 
Table 2- Topics identified based on the reading of abstracts.

\begin{tabular}{|c|c|c|}
\hline Topic & $\mathbf{N}$ & Description \\
\hline $\begin{array}{l}\text { Dynamics of } \\
\text { relationships }\end{array}$ & 149 & $\begin{array}{l}\text { Processes arising from relationships between two } \\
\text { generational groups, within or outside the family, including: } \\
\text { conflict, closeness, intimacy, union, reciprocity, solidarity, } \\
\text { estrangement, ambivalence, in and out-group } \\
\text { communication, mediation amongst family members, } \\
\text { heritage, generativity, or play. Indicators related to marital } \\
\text { status (e.g., divorce) and types of kinship (e.g., parenthood). }\end{array}$ \\
\hline $\begin{array}{l}\text { Health \& } \\
\text { Wellbeing }\end{array}$ & 109 & $\begin{array}{l}\text { Dimensions of life including physical, emotional and } \\
\text { psychosocial, whether clinical or not. Indicators include: } \\
\text { self-esteem, autonomy, confidence, social support, social } \\
\text { skills, stress, dementia, depression and adjustment to life } \\
\text { stages and/or situations. }\end{array}$ \\
\hline $\begin{array}{l}\text { Learning \& } \\
\text { Literacy }\end{array}$ & 75 & $\begin{array}{l}\text { Transfer of knowledge and learning, including both hard and } \\
\text { soft skills such as reading and literacy. Development of } \\
\text { artistic skills and creativity. }\end{array}$ \\
\hline Attitudes & 53 & $\begin{array}{l}\text { Attitudes, stereotyping, prejudice and misconceptions of one } \\
\text { generational group towards another (e.g., attitudes towards } \\
\text { ageing). }\end{array}$ \\
\hline Culture & 45 & $\begin{array}{l}\text { Objective and subjective cultural aspects such as religion, } \\
\text { language, values, and cultural capital, including its } \\
\text { transmission across generations }\end{array}$ \\
\hline Digital & 33 & $\begin{array}{l}\text { Use of digital technologies such as computers, the internet, } \\
\text { social media and social network websites, videos games, as } \\
\text { well as telecommunication media like the television, } \\
\text { telephone or photography. }\end{array}$ \\
\hline Space & 24 & $\begin{array}{l}\text { Influence of socio-spatial conditions on intergenerational } \\
\text { relations (e.g., co-residence, neighbourhood and } \\
\text { communities, rural vs urban). }\end{array}$ \\
\hline $\begin{array}{l}\text { Professional } \\
\text { development }\end{array}$ & 21 & $\begin{array}{l}\text { Intergenerational interactions, relations and/or } \\
\text { communication in the context of the workplace or within } \\
\text { professional development (of both students and workers). } \\
\text { Professional-development activities can be promoted via the } \\
\text { curriculum activities, training or via informal activities. }\end{array}$ \\
\hline $\begin{array}{l}\text { Gender \& } \\
\text { Sexual } \\
\text { Orientation }\end{array}$ & 15 & $\begin{array}{l}\text { Issues of femininity or masculinity, and sexual orientation } \\
\text { (e.g., homosexuality), and how these relate with } \\
\text { intergenerational interactions. }\end{array}$ \\
\hline
\end{tabular}

Note. Topics are not mutually exclusive. The total number of studies was 324 . 
Table 3 - Relationship between Topics and Familial/Non-Familial studies.

\begin{tabular}{lllll}
\hline Topic & $\begin{array}{l}\text { Familial } \\
(\mathrm{N})\end{array}$ & $\begin{array}{l}\text { Non- } \\
\text { Familial (N) }\end{array}$ & Chi-Squared test \\
& 132 & 17 & $\mathrm{X}^{2}(1)=121.9$ & $* *$ \\
\hline Dynamics of Relationships & 65 & 44 & $\mathrm{X}^{2}(1)=1.1$ & $\mathrm{NS}$ \\
Health \& Wellbeing & 21 & 54 & $\mathrm{X}^{2}(1)=30.0$ & $* *$ \\
Learning \& Literacy & 13 & 40 & $\mathrm{X}^{2}(1)=24.7$ & $* *$ \\
Attitudes & 32 & 13 & $\mathrm{X}^{2}(1)=5.1$ & $*$ \\
Culture & 13 & 20 & $\mathrm{X}^{2}(1)=3.9$ & $*$ \\
Digital & 18 & 6 & $\mathrm{X}^{2}(1)=4.0$ & $*$ \\
Space & 0 & 21 & & a \\
Professional Development & 10 & 5 & $\mathrm{X}^{2}(1)=0.8$ & $\mathrm{NS}$ \\
Gender \& Sexual Orientation & 10 & & & \\
\end{tabular}

Note. $*$ Significant: $\mathrm{p}<.05 ; * *$ Highly significant: $\mathrm{p}<.001 ;$ NS Not significant; ${ }^{\mathrm{a}}$ Insufficient data 


\begin{tabular}{|c|c|c|c|c|c|}
\hline $\begin{array}{l}\text { First author \& } \\
\text { Year \& Setting }\end{array}$ & $\begin{array}{l}\text { Age of group(s) } \\
\text { included in } \\
\text { analyses }\end{array}$ & $\begin{array}{l}\text { Programme } \\
\text { duration \& } \\
\text { frequency }\end{array}$ & Programme activities & Main outcome(s) & Main findings (effectiveness) \\
\hline $\begin{array}{l}\text { Belgrave (2011), } \\
\text { adult living } \\
\text { facility (US) }\end{array}$ & $\begin{array}{l}21 \text { young } \\
\text { people (avg age } \\
9 \text { ); } \\
26 \text { older adults } \\
\text { (avg age } 84-85 \text { ) }\end{array}$ & $\begin{array}{l}2.5 \text { months, } \\
\text { weekly for } \\
30 \text { minutes }\end{array}$ & $\begin{array}{l}\text { Singing, structured } \\
\text { conversations, } \\
\text { instrument playing, } \\
\text { body movement } \\
\text { activities. }\end{array}$ & $\begin{array}{l}\text { a) Attitudes of children towards } \\
\text { older adults } \\
\text { b) Children's comfort interacting } \\
\text { with non-familial older adults } \\
\text { c) older adults' attitudes to children } \\
\text { d) Older adults' perceived } \\
\text { psychosocial well-being }\end{array}$ & $\begin{array}{l}\text { a), b), d) NS } \\
\text { c) Older adults in experimental group held } \\
\text { significantly more positive attitudes toward } \\
\text { children, } U(14,12)=36, p<.02 \text {, }\end{array}$ \\
\hline $\begin{array}{l}\text { Chase (2011), } \\
\text { college (US) }\end{array}$ & $\begin{array}{l}43 \text { young } \\
\text { people (mean } \\
\text { age } 20-21)\end{array}$ & $\begin{array}{l}1.5 \text { months, } \\
\text { weekly for } \\
15 \text { minutes }\end{array}$ & $\begin{array}{l}\text { Student and older adult } \\
\text { pairs emailed each } \\
\text { other weekly. Email } \\
\text { topics chosen to } \\
\text { increase in depth and } \\
\text { level of sharing. }\end{array}$ & $\begin{array}{l}\text { a) Student attitudes towards older } \\
\text { adults }\end{array}$ & $\begin{array}{l}\text { a) Intervention students scored significantly more } \\
\text { positive in attitudes toward older adults, } \\
\mathrm{F}(42,23)=14.694 \mathrm{p}<.05\end{array}$ \\
\hline $\begin{array}{l}\text { Dunham (2009), } \\
\text { elementary and } \\
\text { junior high } \\
\text { school (US) }\end{array}$ & $\begin{array}{l}380 \text { young } \\
\text { people (age } \\
\text { range } 4-14)\end{array}$ & $\begin{array}{l}3.5 \text { months, } \\
\text { various } \\
\text { times a } \\
\text { week, } \\
10 \mathrm{~h} / \text { week }\end{array}$ & $\begin{array}{l}\text { Seniors trained to } \\
\text { supplement teacher's } \\
\text { work during class } \\
\text { projects with students }\end{array}$ & $\begin{array}{l}\text { a) Children's attitudes towards } \\
\text { aging and the elderly }\end{array}$ & $\begin{array}{l}\text { a) Children in experimental classrooms had } \\
\text { significantly more positive attitudes toward older } \\
\text { adults on four out of the five attitude measures, } \\
\mathrm{p} \leq .05 \text {; in one of the attitude measures ('feelings } \\
\text { about being old') children in con group had more } \\
\text { positive feelings, } p \leq .05\end{array}$ \\
\hline $\begin{array}{l}\text { George (2011), } \\
\text { intergenerational } \\
\text { school (US) }\end{array}$ & $\begin{array}{l}15 \text { older adults } \\
\text { with dementia } \\
\text { (avg age } 81 \text { to } \\
85 \text { years) }\end{array}$ & $\begin{array}{l}5 \text { months, } \\
\text { every } \\
\text { fortnight for } \\
90 \text { minutes }\end{array}$ & $\begin{array}{l}\text { With kindergarten } \\
\text { children - singing, } \\
\text { reading and writing } \\
\text { activities; with the } \\
\text { sixth grade classroom - } \\
\text { life-history } \\
\text { reminiscence sessions }\end{array}$ & $\begin{array}{l}\text { Older adults': } \\
\text { a) cognitive functioning } \\
\text { b) stress } \\
\text { c) depression } \\
\text { d) sense of purpose } \\
\text { e) sense of usefulness }\end{array}$ & $\begin{array}{l}\text { a), c), d), e) NS } \\
\text { b) Participants in intervention group had a } \\
\text { significant decline in stress levels compared to } \\
\text { those in control group }(p=0.01)\end{array}$ \\
\hline
\end{tabular}




\begin{tabular}{|c|c|c|c|c|c|}
\hline $\begin{array}{l}\text { Pinquart (2000), } \\
\text { senior centres } \\
\text { (country } \\
\text { unclear) }\end{array}$ & $\begin{array}{l}32 \text { children (avg } \\
\text { age } 9) ; 20 \text { older } \\
\text { adults (avg age } \\
71)\end{array}$ & $\begin{array}{l}1.5 \text { months, } \\
\text { weekly for } \\
90 \text { minutes }\end{array}$ & $\begin{array}{l}\text { Child and older adult } \\
\text { pairs wrote stories, } \\
\text { made glove puppets } \\
\text { and performed a } \\
\text { puppet show. }\end{array}$ & $\begin{array}{l}\text { a) Children's attitudes to older adults } \\
\text { b) Older adults' attitudes to children } \\
\text { c) Children's self-concept } \\
\text { d) Older adults' self-concept }\end{array}$ & $\begin{array}{l}\text { a), c), d) NS, } \\
\text { b) Older adults' attitudes towards children improved } \\
\text { significantly in experimental group, F }(2,30)=5.15, \\
\text { p }<.01 \\
\text { Follow-up ( } 7 \text { weeks): a), b), c), d) NS }\end{array}$ \\
\hline $\begin{array}{l}\text { Thompson } \\
\text { (2016), } \\
\text { elementary } \\
\text { schools (US) }\end{array}$ & $\begin{array}{l}944 \text { young } \\
\text { people (avg age } \\
16)\end{array}$ & $\begin{array}{l}\text { Ongoing, } \\
\text { weekly for } \\
6 \mathrm{~h}\end{array}$ & $\begin{array}{l}\text { Children interview an } \\
\text { older adult (e.g. } \\
\text { grandparent) before } \\
\text { each session. Older } \\
\text { adult volunteers come } \\
\text { to the classroom to } \\
\text { discuss with children } \\
\text { how their } \\
\text { interviewees' stories } \\
\text { relate with their own. }\end{array}$ & a) Student's images of aging & $\begin{array}{l}\text { Follow-up ( } 5 \text { to } 9 \text { years after programme): } \\
\text { a) Exp students held a more positive image of older } \\
\text { adults, } \beta=0.126, \mathrm{SE}=0.063 \text {, beta }=0.055, \mathrm{p}<.05 \text {, but } \\
\text { no differences between exp and con in terms of } \\
\text { their negative images of aging; }\end{array}$ \\
\hline $\begin{array}{l}\text { Low (2015), } \\
\text { adult living } \\
\text { facility } \\
\text { (Australia) }\end{array}$ & $\begin{array}{l}21 \text { children } \\
\text { (aged } 4) ; \\
40 \text { older adults } \\
\text { with dementia } \\
\text { (avg age } 91 \\
\text { years) } \\
\end{array}$ & $\begin{array}{l}3 \text { months, } \\
\text { weekly for } \\
45 \text { minutes }\end{array}$ & $\begin{array}{l}\text { Each child was paired } \\
\text { with an older adult to } \\
\text { participate in a range } \\
\text { of activities together } \\
\text { such as discussions, } \\
\text { crafts and games. }\end{array}$ & $\begin{array}{l}\text { Older adults': } \\
\text { a) quality of life } \\
\text { b) agitation } \\
\text { c) sense of community }\end{array}$ & $\begin{array}{l}\text { One week after end of programme: } \\
\text { a), b), c) NS }\end{array}$ \\
\hline $\begin{array}{l}\text { Murayama } \\
\text { (2015), nursery } \\
\text { to high schools } \\
\text { (Japan) }\end{array}$ & $\begin{array}{l}80 \text { older adults } \\
\text { (avg age 69) }\end{array}$ & $\begin{array}{l}\text { Ongoing, } \\
\text { every } 1 \text { to } 2 \\
\text { weeks, } 15 \text { to } \\
30 \text { minutes }\end{array}$ & $\begin{array}{l}\text { Older adults read } \\
\text { picture books to } \\
\text { children and play a } \\
\text { hand game }\end{array}$ & $\begin{array}{l}\text { Older adults': } \\
\text { a) depressive mood } \\
\text { b) sense of coherence } \\
\text { c) comprehensibility } \\
\text { d) manageability } \\
\text { e) meaningfulness }\end{array}$ & $\begin{array}{l}\text { Follow-up ( } 9 \text { months to } 3 \text { years after baseline): } \\
\text { a), b), c), d) NS at } .05 \text { level } \\
\text { e) Sense of meaningfulness significantly increased } \\
\text { for members of the intervention group over time, } \\
\text { compared to con participants (p }<.05 \text { ) }\end{array}$ \\
\hline $\begin{array}{l}\text { Sakurai (2016), } \\
\text { nursery to high } \\
\text { schools (Japan) }\end{array}$ & $\begin{array}{l}162 \text { older adults } \\
\text { (avg age } 66 \text { ) }\end{array}$ & $\begin{array}{l}\text { Ongoing, } \\
\text { every } 1 \text { to } 2 \\
\text { weeks, } 15 \text { to } \\
30 \text { minutes }\end{array}$ & $\begin{array}{l}\text { Older adults read } \\
\text { picture books to } \\
\text { children and play a } \\
\text { hand game }\end{array}$ & $\begin{array}{l}\text { Older adults': } \\
\text { a) physical functions ( } 5 \text { functions) } \\
\text { b) lifestyles and psychological } \\
\text { variables } \\
\text { c) functional capacity }\end{array}$ & $\begin{array}{l}\text { Follow-up ( } 7 \text { years): } \\
\text { a) One physical function greater in exp group } \\
\text { ( } \mathrm{p}=.007) \text {; NS in other four functions } \\
\text { b) Con group had fewer interactions with } \\
\text { neighbourhood children (OR: } 3.79 ; 95 \% \mathrm{CI}: 1.60 \text { - } \\
9.00, \mathrm{p}=.003) \text {; Exp group went outdoors less } \\
\text { frequently (OR: } 0.36 ; 95 \% \text { CI: } 0.13-0.98, \mathrm{p}=.045) \text {, } \\
\text { c) Con group at greater risk of intellectual activity } \\
\text { impairment (OR: } 10.6 ; 95 \% \text { CI } 1.64-68.6, p=.013 \text { ) }\end{array}$ \\
\hline
\end{tabular}


Note. NS=Non-significant difference between intervention and control groups. Murayama and Sakurai reported two different studies from the same programme. 